\title{
The connection between environmental awareness and socio-economic and cultural structure
}

\author{
B. Üstün ${ }^{1,2} \&$ B. Celep ${ }^{2}$ \\ ${ }^{I}$ Department of Environmental Engineering, \\ Ylldiz Technical University, Turkey \\ ${ }^{2}$ Institute of Environmental Sciences, Bosphorus University, Turkey
}

\begin{abstract}
The ecosystem encompasses both social and natural systems. There is a permanent relationship between these two systems based on their impacts on each other. These impacts are a result of social, political, economical and cultural conditions in society. These factors are also important for the determination of the environmental awareness in any region. In order to show the relationship between environmental awareness and these factors, a study of questionnaire has been made in Küçükçekmece Watershed. This area is the basin of one of the most important water resources, called Küçükçekmece Lake, in İstanbul. The majority of people coming to live in Istanbul have chosen to settle in this area. Today, the watershed is under a very serious pollution load. The results of the study made in the region have showed that socio-economic and cultural structures of the people affect their environmental awareness and their impacts on the region.
\end{abstract}

Keywords: environmental awareness, socio-economic factors, cultural structure, natural system, social system.

\section{Introduction}

Ecosystem is a whole covering different kinds of biotic organisms and their abiotic environment [1]. This main system covers both social system which is formed by human based groups such as families, communities and several institutions [2], and natural system which is formed by the relationships of non- 
human elements and is based on their own dynamics and abiotic, biotic and chemical processes [3].

Today, environmental pollution and problems pose a serious threat to the sustainability of ecosystem. The investigation of both reasons and effects of these pollution and problems and determination of the ways of their control can be achieved by considering the conditions in both parts of ecosystem, social and natural. This situation makes necessary the consideration of social, economic, political and cultural factors in social system as much as physical, chemical and biological phenomena in natural system. The reason of this situation is the structure of ecosystem depending both social and natural system and the presence of a permanent relationship between these two systems. This permanent relationship between the systems is shaped by the impacts of them on each other.

Human being has to meet the needs of food, water and shelter to survive. In order to meet such needs, he is benefited from natural resources [4]. This is the positive impact of natural system on social system. However, the environmental phenomena such as earthquake, volcanic eruption, floods or climate changes in natural system can lead to the formation of the conditions threatening the continuity of human life [5] and can adversely affect social system with the negative and deep results of these phenomena.

Another part of the interaction between two systems is the impacts of social system on natural system. The human beings play a role in the formation of some environmental events through some of their decisions and applications. In addition to the impact based on the contribution of people to the generation of environmental events, human beings can reduce the absorb capacity of ecosystem to environmental phenomena through the factors such as population increase, uncontrolled industrialization and/or poor land management [6]. This situation makes the natural system weaker, much more vulnerable and gives rise to increasing adverse impacts of social system on natural system.

The factors, generating different parts of the web of relationships between social and natural system, such as the amount and variety of natural resources which are demanded from natural system by human beings, the degree of resilience and vulnerability of human beings to the environmental occurrences, the conditions which cause people to make decisions affecting the environment or the human activities such as uncontrolled industrialization and unplanned urbanization which increase the vulnerability of natural system by decreasing the absorb capacity of ecosystem, are a result of social, economic, political and cultural conditions in the society.

In the solution and control of environmental pollution and problems, the consideration of these social, economic, political and cultural conditions can be accepted as the most convenient and correct application.

\section{The relationship between environmental awareness and socio-economic factors}

The degree of environmental concern which is associated with the factors such as education, income, age, and gender is an important criterion for the assessment 
of environmental awareness of the people. High environmental concern in a society shows the presence of human beings who are deeply interested in the environmental matters and have high level of environmental awareness. As a result of such a link between environmental concern and awareness, the factors, associated with environmental concern, can also be accepted as directly related to environmental awareness.

\subsection{Education}

Environmental concern and education are positively associated with each other [7-9]. The positive impacts of education on environmental concern of the human beings are linked to the contributions of education to the relationships of people with the outside world.

As it was explained in previous years, with the raising education level, people have improved ability to comprehend complex environmental problems as a result of a higher level of awareness of public affairs based on increasing cognitive skills. With education, people can come into contact with other individual's who have different values, opinions and worldviews and become more open to new ideas and value systems. Such an improvement makes easier the acceptance of environmentalism for these people [10].

\subsection{Income}

Environmental concern is positively associated with income. The priorities of lower income people are more likely to meet the basic needs of their own or families [7] and concern for environmental issues can be ignored when compared with meeting these basic needs. However, higher income people have the proper conditions for meeting the basic needs such as adequate nutrition or health care [10]. That's why, it is much more possible to be interested in environmental issues for them when compared to the lower income people.

\subsection{Age}

Age is the strongest and most consistent predictor of environmentalism [9]. It is negatively associated with environmental concern. The control of environmental pollution and solution of environmental problems make necessary some structural changes in the society. While the older people are not open to new ideas and they do possibly not want to change the existing system, the young people are ready to and enthusiastic for new world views and value systems and they easily support the birth of new issues like environmental concern [10].

\subsection{Gender}

There was no a certain idea about who has stronger environmental concern: men or women for long years [7].

Actually, men have become in education life and more active in social life for longer years when compared to women. That's why, it is expected that men are 
much more concerned with environmental issues than the women. But, because of the father effect and having opportunities for monetary gains for long years, meeting the economic needs of their families are much more important for the men than becoming concerned with environmental issues. The situation is different for the women. The environmental problems or pollution can lead to the generation of conditions threatening the life of their families. As a result of mother effect and generally having much more social responsibility than the men, they prefer to be concerned with the environmental issues [10].

\section{The relationship between environmental awareness and culture}

The definition of culture has been given in many studies with different approaches. The most common point of these definitions is the great role of human activity in the formation of a cultural structure of a society. Culture can be defined as "patterns of human activity and the symbolic structures that give such activity significance", "the way of life for an entire society", "a complex whole including knowledge, belief, art, morals, law, custom, and any other capabilities and habits acquired by man as a member of society" [11]. With another approach based on mental and spiritual link among the members of a society, culture can be defined as "shared belief systems between different social groups" or "the collective programming of the mind which distinguishes one group from another" [12].

The relationship between culture and environmental awareness can be explained by the effects between social system and natural system. As it has been explained above, human being can play a role in the generation of some environmental phenomena through some of his decisions and applications or he can reduce the absorb capacity of the ecosystem with the factors such as population increase, uncontrolled industrialization and/or poor land management. On the other hand, while the environment affects the social system positively through the supply of natural resources, it can also adversely affect human life through the results of the environmental phenomena. During these relationships, for the sustainability of the ecosystem, it is expected from the human beings, the preference of the activity which harms the environment as least as the possible. Such a way of activity may be indicator of presence of high environmental concern and awareness. The decisions, activities and applications which give idea about the level of environmental awareness of the people, are a result of not only their socio-economic conditions but also their cultural structure which can also be shaped with respect to these socio-economic conditions. Human being will give a decision as a result of the factors such as his knowledge, belief, intellectual and emotional features and will show his environmental concern and awareness by this way.

In the light of the explanations above, the relationship between culture and environmental awareness can be explained by the term of value or value system in the lives of the people. 
In the last century, social psychologists have investigated "general attitudes about environmental issues" [13] and they measured "an individual's degree of concern for human caused environmental problems" through a variety of scales developed by Weigel and Weigel (1978), Lounsbury and Tornatzky (1977), Maloney and Ward (1973), Maloney et al. (1975), and Dunlap and Van Liere (1978) [14]. During this process, a value basis theory for environmental concern was developed by Stern and Dietz as a result of investigations of the values as the basis for environmental attitudes [14]. According to this theory, as a result of the set of values of human beings, there are three kinds of environmental attitudes in the society: Egoistic, Social - altruistic and Biocentric [15]. They are shaped by consideration of individualistic interests, benefits of other people and all living things, respectively. The priorities of these concepts in the value system of the people show the level environmental concern and awareness of the human beings.

The term of value is also important for the definition of culture like for the determination of environmental concern and awareness. Value is one of the components of culture and shows "what in life seems important" [11]. When the relationship among value system, environmental concern and awareness is considered, the role of the term of value in the definition of culture can be accepted as a hint for the existence of the relationship between culture and environmental awareness.

\section{Socio-economic and cultural structures in Küçükçekmece region}

Küçükçekmece Lake is one of the most important water resources in İstanbul because both it is a natural lagoon system and particularly in the past, it included a lot of species. Today, Küçükçekmece Lake and watershed is under a serious pollution load due to the several factors such as rapid industrialization, high rate of population increase, and unplanned settlement.

Today, Watershed has become a region where a high number of different groups which have different values, live together as a result of the migrations from almost each region of Turkey. As a consequence, there is a cosmopolitan population, consisting of the people who have different socio-economic conditions and cultural structure.

\subsection{Socio-economic structure in Küçükçekmece region}

Socio-economic structure in any area is evaluated by analyzing the factors such as education, income, age, and gender.

In order to determine the socio-economic structure and environmental awareness of the residents in Küçükçekmece Region, the method of questionnaire was used and 1100 people were interviewed in the basin. At the end of the interviews, it has become possible to reach a general information about the level of education and income and distribution of occupation and gender in the basin in addition to the level of environmental awareness. 
When the level of the education of the interviewees is analyzed, it has been seen that there are people from different levels of education from primary school to university. However, while the ratio of the people who graduated primary school is $46,22 \%$, the ratio of the people who graduated high school and university, $23,66 \%$ and $8,46 \%$ respectively. These numbers show that the level of education of the people in the basin is very low.

In the questionnaire study, the selected lowest and highest limits of monthly income levels were 500 NTL and 1000 NTL and above this upper limit, respectively. According to the responds of the interviewees, the ratio of $42,22 \%$ of the interviewees gain either 500 NTL or below this amount. The ratio of the people who gain 1000 NTL or above this amount is just 18,93\%. These results show that the levels of income of interviewees in the basin are insufficient for having good life conditions.

The $42,31 \%$ of the interviewees has determined his occupation as freework. $25,93 \%$ of the participants to the study are housewife. These groups of occupation do not need a qualified or well-educated people. The ratios of the occupations which need for university degree are very low when compared to the ratios of freework or housewife such as $1,91 \%$ or $0,09 \%$ for teacher and attorney, respectively.

The gender distribution of the interviewees is $63,51 \%$ and $36,31 \%$ for men and women, respectively [10].

\subsection{Cultural structure in Küçükçekmece region}

In Küçükçekmece Watershed, there are a large number of different groups who have different value and belief systems. It is possible to see the basis of the differences among the groups by consideration of the cities or countries where the immigrants come from. The immigrants have come from European Turkey in 1950s, from different parts of Anatolia in different dates especially since the 1980s and particularly from East and South East part of Anatolia since the second half of the 1990s [16].

During the migrations from European Turkey, Küçükçekmece Watershed was a region where the settlement was very rare, the large and empty areas were easily found and there was no any kind of environmental problem in the watershed. The houses of these immigrants were generally two flat buildings and they were legally constructed. These immigrants, with the impact of the sincere but much more formal relationships when compared to the human relations of today, have acted by considering the benefits of each other, their neighbors and the place where they lived. Keeping the watershed clean is a normal responsibility for them not an avoidable one.

Although the initial residents in the watershed came generally from these countries, today, a major part of the population in the watershed is composed of the people who have come from different parts of Anatolia. When the cultural structure of these people is explored, it is seen that a particularly different cultural character are seen in the people who especially come from East and South East Anatolia. The most common feature of these people is the way of 
coming to the watershed. According to the lifestyle of these people, initially, a member of the family comes to the region, he settles and after a certain period of time, he helps the other members of the family and relatives come to the same region to live. Today, in some houses in the parts of the watershed where these immigrants live, more than ten people live in the same flat of the same building. They have large number of children more than five. They try to continue the life style in their village with each kind of habit or rule. That's why, they do not hesitate to organize the street weddings which last three days, they cut sheep or make bread in traditional ways without considering the disturbing effects of these events for the other people living in the same region, the adverse environmental results and the lack of sanitary conditions.

Although the most dominant characteristics of the immigrants coming from East and South East Anatolia as mentioned above, the most of the people coming from different parts of Anatolia and East and South East Anatolia have also some common living habits. They shape their environments according to their local culture and lifestyles, do not permit the local authorities for the rehabilitation of the places where they live, lead to lost environmental, cultural and historical values with their lifestyle and form neighborhoods illegally [17].

Consequently, today, Küçükçekmece Watershed is a region where people who have mostly low level of education and low or moderate level of income. It is possible to see different cultural structures in the watershed due to the migrations from European Turkey and several parts of Anatolia in different dates.

\section{Conclusion}

As it is explained above, a questionnaire study was made in the watershed with 1100 people. The responds were evaluated in terms of environmental awareness by considering the social and economic situations of the interviewees. Contrary to the common relationship between socio-economic factors and environmental awareness, in Küçükçekmece Watershed, poorly-educated people do not show a lower level of environmental concern and awareness when compared to the responds of the people who graduate high school or university. The same kind of relationship has also been seen between the people who have high and low level of income.

The differences in the cultural structure of the people in the watershed are closely linked to the cities or regions from where they come. The responds are evaluated with consideration of this relationship. Consequently, it has been seen that, while the people who come from European Turkey show a higher level of environmental concern and awareness with their lifestyle, the people especially come from East and South East Anatolia do generally not care environment and other people who live in the same area. They have low level of environmental awareness. It is possible to reach such a result when it is observed their way of living. 


\section{References}

[1] Ünal, S., \& Mançuhan, E. \& Sayar A., Environment in ecology (Section 2 - Chapter 5). Environmental Conscious, Knowledge and Education, ed. Engineering Faculty of Marmara University, pp. 52, 2001.

[2] The Occupation of Social Service, The Approaches and Occupational Ethic, www.sosyalhizmetuzmani.org/sosyalhizmetetigi.doc

[3] www.akdeniz.edu.tr/muhfak/cevre/coastlearn-r/intro/newprinciplesiczm/ $\mathrm{html} /$ poficzm-systemsview.htm

[4] Me-Bar, Y. \& Valdez Jr., F., On the vulnerability of the ancient Maya society to natural threats. Journal of Archaeological Science, 32, pp. 813$825,2005$.

[5] Metzger, M. J. \& Rounsevell, M.D.A. \& Acosta-Michlik, L. \& Leemans, R. \& Schröter, D., The vulnerability of ecosystem services to land use change. Agriculture Ecosystems \& Environment, 114, pp. 69-85, 2006.

[6] Rockström, J., Resilience building and water demand management for drought mitigation. Physics and Chemistry of the Earth, 28, pp. 869-877, 2003.

[7] Influences on Environmental Concern: Identifying Cross-National Similarities. Www.uni-bielefeld.de/iwt/eesn/Marquart_pyatt_2005_ESA. pdf

[8] Gökşen, F. \& Adaman, F. \& Zenginobuz, E. Ü., On environmental concern, willingness to pay, and postmaterialist values: evidence from İstanbul. Environment and Behavior, 34(5), pp. 616-633, 2002.

[9] Dietz, T. \& Stern, P. C. \& Guagnano, A., Social structural and social psychological bases of environmental concern. Environment and Behavior, 30(4), pp. 450-472, 1998.

[10] Yilmaz, S. \& Yaman, S. \& Alkaya, İ., The impact of socio-economic structure on environmental awareness in Küçükçekmece Basin. BSc Thesis, Y1ldiz Technical University, 2006.

[11] http://en.wikipedia.org/wiki/Culture

[12] Leong, C. H. \& Ward, C., Cultural values and attitudes toward immigrants and multiculturalism: the case of the Eurobarometer survey on racism and xenophobia. International Journal of Intercultural Relations, 30, pp. 799810, 2006.

[13] Schultz, P. W. \& Zelezny, L., Values and predictors of environmental attitudes: evidence for consistency across 14 countries. Journal of Environmental Psychology, 19, pp. 255-265, 1999.

[14] Schultz, P. W, The structure of environmental concern: concern for self, other people, and the biosphere. Journal of Environmental Psychology, 21, pp. 327-339, 2001.

[15] Snelgar, R. S., Egoistic, altruistic, and biospheric environmental concerns: measurement and structure. Journal of Environmental Psychology, in press. 
[16] Karakaş, M. \& Tabak, S., The determination of the reasons of the pollution in Küçükçekmece Lake and basin. BSc Thesis, Yıldız Technical University, 2005.

[17] Kaya, İ. \& Zengel R., A marginal place for the Gypsy community in a prosperous city: Izmir, Turkey. Cities, 22(2), pp. 151-160, 2005. 